\title{
CONTRACTING IN INTERMEDIATE MARKETS*
}

\author{
Paulo C. Coutinho**
}

\section{ABSTRACT}

This paper builds three models for intermediate industrial product markets characterized by a monopolist seller and many competitive buyers in an environment with uncertainty and asymmetric information. In the main model the paper analyses credible announcement equilibria, i.e., rational expectations equilibria of the following type. The uninformed agent makes some announcement about how he will act after some information is transmitted to him by the informed agents. Even though he is allowed to behave differently from his announcement, it turns out in a credible announcement equilibria that it is in the best interest of the uninformed agent to fulfill his announcement.

*The author is very grateful to Costas Azariadis, Richard Kihlstrom and Michael Riordan for their continuous incentive to this work and the detailed comnents. He has also profited from discussions with Richard Mc Lean, Fernando Saldanha, Hugo Sonnenchein, Joseph Stiglitz and Oliver Williamson. However he has full responsibility for any remaining errors.

Instituto de Natemática Pura e Aplicada - IMPA. 


\section{INTRODUCTION}

The importance of long-term contracts in resources allocation in the areas of agriculture and the market for foreign currencies has long been recognized by the economic profession. Recently, Stigler and Kindahl (1970) forcefully argued that this phenomenon is more pervasive. They pointed out that (long-term) ${ }^{1}$ contract transactions are present in the market for almost all intermediate industrial products, together with an operative spot market.

There exists a large body of economics literature which analyses contracting relations, but we are not aware of any work addressing the issue of coexistence of spot and long-term (i.e., non spot) contract market.

The Keynes-Hicks theory of contract as means of hedging risk-averse traders against future uncertainty is of limited interest for intermediate product market transactions. In those markets, typically both parts of the transaction are firms. In those situations, the assumption of risk-aversion is not very natural and it would help if other explanations could be found for the occurrence of forward transactions which do not rely on risk-aversion properties. In the models we build in this paper, we assume that firms are risk-neutral.

1 The terms "long-term contract" and "contract" are used interchangeably. 
In the models where the source of incentive to open contract markets is difference in beliefs (or asymmetry of information), as in Grossmam (1977, 1981) and Hirshleifer (1971), the existence of spot markets is assumed from the beginning. Also, in these models risk-aversion plays an important role. If agents were risk-neutral and had different beliefs about the future, which means different expected future price of some good, then they would be willing to buy (or sell) an infinite amount of the good today if contract price were different from expected spot price. Since agents have different expected spot price, there would not be any price which would equilibrate the contract market. The important role of risk-aversion in these models is to make individual demand (or supply) well behaved. However, as we argued in the preceding paragraph, risk-aversion is an assumption which is not convenient in intermediate product markets.

In our models the role played in Grossman-Hirshleifer models by the risk-aversion assumption will be played by the assumption that it is not possible to resell the good transacted. The justification for this assumption is that goods are perishable (or have high inventory cost) and are useful only for who have bought them. (This is the case of goods that can be tailored to the customer's specification). Therefore the three key assumptions of our models are risk-neutrality, asymmetry of information and impossibility of reselling.

In the "optimal contracting" literature (Azariadis (1975, 1983), Chari (1983), Green and Kahn (1983), Grossman and Hart (1983)), usually there is no spot market. This is also true in the transactions cost literature (Wachter and williamson (1978), Williamson (1979), which focuses on contracting of non-standard products, where usually there is no spot market.

In contrast to the previous literature we wish to focus on the reasons why we observe both spot and contract markets for the same industrial intermediate product. We try to identify structural conditions which, if they are satisfied in many markets, should not surprise us in observing both markets actively operating. 
In order to address this issue, we build three models. They all share some basic common structure, but differ in how transactions can be made. There is one monopolist seller and many competitive buyers. Buyers use the intermediate product as an input for the production of a final good; they face random demand for their (final) good, about which they have some advance information. The seller's production function takes one period of time. Prices under which transactions are made are announced by the monopolist seller. Each buyer has discretion about how many units of the product he wants to buy.

In the first model there is no contract market. Transactions are made only on the spot. We show that such institutional arrangement performs poorly in terms of using the available information at the time that production decisions have to be made.

In the second and main model, we al.low transactions to be made in both a contract market (for deferred delivery) and in a spot market (for spot delivery). The seller announces both the price for contract transactions for delivery tomorrow and the prices for spot transactions tomorrow. However, when tomorrow comes, if it is in the best interest of the seller to charge spot prices different from his (yesterday) announcement, he will.

This "non-binding announcement", together with the rational expectations hypothesis, implies a property similar to the "revelation principle" developed in game theory las in Myerson (1979)). Here, the rational expectations hypothesis implies that the seller is restricted to announce today spot prices which are credible, i.e., spot prices announcements such that if the buyers believe in the seller's announcement, the best the seller can do is to fulfill his announcement. We characterize the equilibria in such a model and show that the equilibrium dominates the equilibrium of the model with only spot market, from the viewpoint of the seller. In this characterization we relate the credible announcement equilibrium with fully informed mcnopolistic equilibrium and fully informed competitive equilibrium. We also 
characterize cases in which both spot and contract markets are operative, i. e., cases when a strictly positive number of goods is transacted in each market at equilibrium.

The third model developed differs from the second only by the fact that the seller is now bound by his announcement, i. e., if he announces today that tomorrow's spot price will be $x$ dollars, then he must charge $x$ dollars tomorrow. This "binding announcement", constraint expands rather than contracts the seller's choice set in the second model developed. Therefore, we have been able to show that an equilibrium in this model dominates an equilibrium in the non-binding announcement model (the second model) from the viewpoint of the monopolist seller. However the choice between market organization as in model 2 or 3 may not be at the discretion of the monopolist seller.

In making the comparison between the equilibrium solutions of the different models, we take the viewpoint of the seller. This is because it is the monopolist who has the power to open or close markets. The competitive buyers take the institutional arrangement as given and solve their maximization problem. The monopolist seller has the institutional arrangement as one of the arguments of his profit function.

As a motivation for our models, we will give an idealized description of a market which the models try to reflect: the market for stel. Stigler and Kindahl (1970) have observed that considering only at rolled carbon sheets, there are more than 137 million varieties of physical attributes. Thus, our idealized market for steel products has each buyer of steel buying stell of different physical specifications. There exists a production lag in the steel production. Buyers of steel products face a random demand for their product, about which they have some advance information as to the likelihood of the different states of nature. The random demands for the products made by the buyers of steel move together (or are correlated). Thus the behavior of one buyer may reveal information not only about his downstream market conditions but also about the downstream market conditions of other buyers of steel. 
In section II we present the general assumptions of the three models. Section III analyses the spot market model. Section IV analyses the credible (i. e., non-binding) announcement model. Section $V$ analyses the binding announcement model. Section VI concludes and gives directions for further research.

\section{GENEKAL ASSUMPTIONS}

In this section we will describe the assumptions which are the backbone of our models (this corresponds to our usage of the word "general" in the tit.le of this section). The models will be developed in the simplest version which can address most or all of the relevant issues that arise in more general environments. ${ }^{2}$ The models which will be developed share the following basic assumptions.

A1. The models have two periods, called today and tomorrow.

A2. There is one monopolist producer and seller of a product, called producer, and a continuum of non-atomic price-taker buyers, called retailers. Retailers are indexed by $\alpha$ and are uniformly distributed in the interval $(0,1)$.

A3. Production process at the producer level takes one period of time, so tomorrow's output is completely determined today. The inventory cost of holding output is infinite. ${ }^{3}$ Retailers' output

${ }^{2}$ By more general environments we mean an arbitrary number of finite different states of nature and information, each agent possibly possessing private information different from the private informa tion possessed by the others, and a general joint distribution of states of nature and information.

${ }^{3}$ Qualitative results would not be changed in inventory costs were finite but bounded away from zero. 
is in one-to-one relationship with the product made by the producer used as input, so we will use the same symbol to represent both the intermediate product and the final good.

A4. Producer and retailers are risk-neutral.

A5. There is no reselling.

No reselling would be implied if the products demanded by the retailers have a trivial idiosyncratic characteristic that makes them of interest only to the firm that initially bought them, like a stamp. The production of this idiosyncratic characteristic does not consume time and is made just before delivery.

A6. Tomorrow's state of nature, designated by $\mathrm{p}_{i}$, is defined as the realization of an infinitely elastic random demand curve for the (final) good. Thus $\mathrm{p}_{i}$ also represents the price of the final good in state of nature $p_{i}$. It can take two different values, $\mathrm{p}_{1}>\mathrm{p}_{2}$, with probatilities $\theta$ and $(1-\theta)$, respectively.

The assumption that there are only two states of nature is made only for simplicity. We strongly believe that the main results will remain true for the case when there are a finite but arbitrary number of states of nature.

A7. Retailers observe today the realization of the random demand curve for the good $\mathrm{p}_{i}$. The producer cannot observe this realization today but knows that retailers have observed it.

A8. Prices for the intermediate product are announced by the producer. Retailers choose the quantity bought. Quantity delivered must equal quantity bought.

This assumption plays an important role since implies that prices cannot reveal information (prices are determined by the non-informed agent) and that quantities may. This assumption may look somewhat ad hoc but we, and other economists, believe that 
this type of price formation is quite common. To quote Rothchild and Stiglitz (1976) "(In) most competitive markets, sellers determine only price and have no control over the amount their customers buy".

A9. Agents have rational expectations in the sense that they correctly forecast future states of the economy (future prices at each state of nature), and use the true probability distribution in their evaluation of the likelihood of the different states of nature.

A10. The producer's cost function is assumed to be of the following form:

$$
C(x)=\frac{b y^{2}}{2}, b>0
$$

A11. Retailers' production process is instantaneous. Retailer a's cost function is composed of two parts: one, a production cost, is

$$
C_{\alpha}(w)=\frac{w^{2}}{4 \alpha}
$$

The other component is the amount he has to pay to the producer in order to buy the intermediate product.

The role played by $A 10$ and $A 11$ is to allow us to make graphical analysis. The qualitative results would remain true if the cost functions $C($.$) and C_{h}($.$) were strictly convex and$ $C_{\alpha}^{\prime \prime}() \leq$.0 . (which implies that the producer will face a decreasing marginal revenue function).

A12. The producer is able to observe only the aggregate demand.

This assumption is natural in an environment of many small and different buyers. The benefit that the producer could obtain from observing each individual buyer's demand curve ought to be 
smaller than the cost of observing it.

We can now investigate how the production-pricing decision would be taken by the producer under three alternative institutional arrangements. Only a spot market. Both spot and contract markets: "credible announcement" equilibrium. Finally, both spot and contract markets: "binding announcement" equilibrium.

\section{ONLY SPOT MARKET}

Because the producer does not know retailers' preferences he cannot price discriminate to his advantage (see spence [1977]), the best he can do is to set a price $r_{i}$ for each state of nature $i$ and let each retailer choose the amount that is going to be transacted.

3. 1. Demand Behavior at State of Nature $p_{i}$

Retailer $\alpha^{\prime} s$ maximization problem is

$$
\max _{x>0} p_{i} x-\frac{x^{2}}{4 \alpha}-r x
$$

with solution

$$
x_{i}^{*}(\alpha)=x_{i}\left(\stackrel{*}{p}_{i}, r_{i}, \alpha\right)=\max \left\{2\left(p_{i}-r_{i}\right) a ; 0\right\}
$$

The aggregate demand at state of nature $p_{i}$ is

$$
x^{*}= \begin{cases}\int_{0}^{1} 2\left(p_{i}-r_{i}\right) \alpha d \alpha=p_{i}-r_{i}, \text { if } p_{i} \geq r_{i} \geq 0 ; \\ 0, & \text { otherwise. }\end{cases}
$$




\subsection{Supply Behavior}

Because the producer has to make his production decision before state of nature is revealed to him, he has to choose two things. First, before observing the state of nature, he has to choose the total amount of output tomorrow y. Second, after observing the realization of the state of nature, he has to choose $x_{i}$, the amount supplied in the spot market in each state of nature $i$ given that he had chosen the capacity constraint $y$. The choice of $y$ is made in order to maximize expected profit. First, we can note that $y=\max \left\{x_{i}\right\}$. If $y>\max _{i}\left\{x_{i}\right\}$, reducing $y$ a sufficiently small amount does no change the revenue in each state of nature

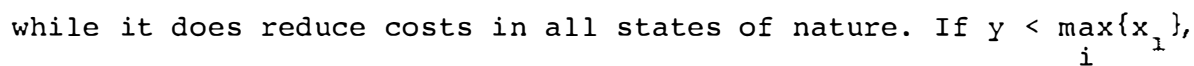
then by increasing the wholesale price in the state of nature with highest $x_{i}$, the revenue in that state of nature would increase. However, it would not affect the revenue in the other state of nature, nor the cost in any state of nature.

Formally, the producer's behavior can be described by ${ }^{4}$

$$
\max _{\mathrm{x}_{1}, \mathrm{x}_{2}} \Theta\left\{\mathrm{r}_{1} \mathrm{x}_{1}-C\left(\max \left(\mathrm{x}_{1}, \mathrm{x}_{2}\right)\right)\right\}+(1-\theta)\left\{\mathrm{r}_{2} \mathrm{x}_{2}-C\left(\max \left(\mathrm{x}_{1}, \mathrm{x}_{2}\right)\right)\right\}
$$

$$
\text { s. } t \text {. }
$$

$$
\begin{aligned}
& r_{1}=p_{1}-x_{2} \\
& r_{2}=p_{2}-x_{2}
\end{aligned}
$$

\footnotetext{
4he expected profit function of the producer may not be everywhere differentiable because his cost function may not be. But we can calculate the expected profit function under three different specifications of the cost function: (a) $C=C(x)$, assuming $x_{1}=x_{2} ;(b) C=C\left(x_{1}\right)$, assuming $x_{1}>x^{2} ;(c) C=C\left(x^{2}\right)$, assuming $x<x^{2}$. At the solution of problem (4), the cost function of problem (4) is equivalent to the cost function of one of the three alternative specifications of the cost function. Needless to say, all three are differentiable.
} 
If at the solution, $x_{1}=x_{2}=x$, then it must be the case that

$$
E[M R(x)]=M C(x)
$$

If at the solution, $x_{1}>x_{2}$, then it must be the case that $\operatorname{MR}_{1}\left(x_{1}\right) \operatorname{Pr}(i=1)=M C\left(x_{1}\right) ;$

$\mathrm{MR}_{2}\left(\mathrm{x}_{2}\right)=0$

If at the solution, $x_{2}>x_{1}$, then is must be the case that $M R_{2}\left(x_{2}\right) \operatorname{Pr}(i=2)=M C\left(x_{2}\right)$

$\operatorname{MR}_{1}\left(x_{1}\right)=0$

Given the structure of the model, the solution of the producer's problem is also the market equilibrium. A typical solution to this problem is presented in Figure $I$ on the next page. $r_{i}^{O}$ represents the equilibrium spot price at state of nature $i$ when there is only the spot market and the (monopolist) producer is uninformed. Let $r_{i}^{m}$ represent the equilibrium spot price at state of nature $i$ when there is only spot market but the producer is fully informed. Let $r_{i}^{c}$ be the equilibrium spot price at state of nature $i$ when there is only spot market, the producer is fully informed but acts like a competitor.

In the equilibrium with only spot market and the producer is uninformed at the time he has to make his production decision $\left(r_{1}^{\circ}, x_{1}\left(r_{1}^{\circ}\right) ; r_{2}^{\circ}, x_{2}\left(r_{2}^{\circ}\right)\right)$, the producer is making a very poor production-pricing decision. As we can observe from Figure $I$, he is over-producing in state 2 while under-producing in state 1 , compared with the production-pricing decision that a fully informed monopolist would make $\left(r_{1}^{m}, x_{1}\left(r_{1}^{m}\right) ; r_{2}^{m}, x_{2}\left(r_{2}^{m}\right)\right)$. 


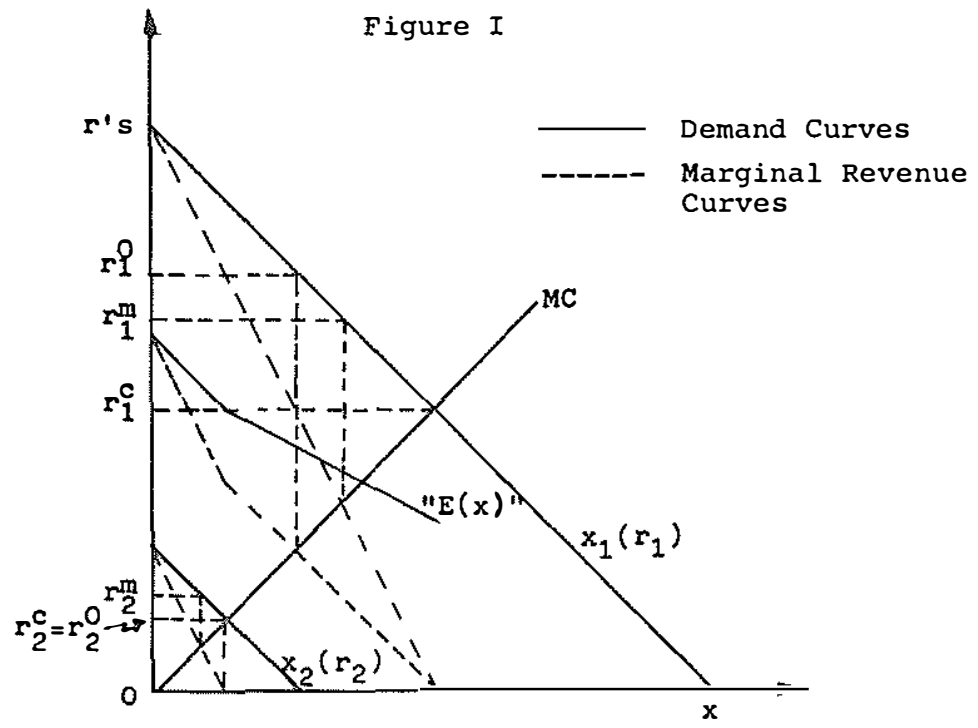

The limitation of this institutional arrangement lonly spot market) is that the producer is not making any use of the information about the likelihood of the different states of nature available in the market at the time he has to make his production-pricing decision. Had he obtained the information possessed by the retailers, he could have made a better production-pricing decision. Thus, there are incentives for the producer to create mechanisms through which retailers' information would be transmitted to him at useful time.

Unfortunately, there are many situations such that the producer cannot obtain for free the available information in the economy. We also know that the opening of a contract market can create the incentive to transfer to the producer at useful time the information present in the economy. In the next sections we investigate how such contract markets could operate, which would be the equilibrium price system, and the relationship between spot and contract price. 
4. BOTH SPOT AND CONTRACT MARKETS:

CREDIBLE ANNOUNCEMENT EQUILIBRIUM

The contract market will be described as: producer today sets a price for quantities bought in advance; retailers choose the quantity (the size of the order). Also, the producer today announces the price that he will charge tomorrow for spot deliveries at each state of nature (the spot price distribution). Given producer's announcement, retailers form their expectations about the true spot price distribution. Given their expectations, they behave in the contract market in order to maximize profits. The role of the assumption that the producer announces today the spot price distribution is to serve as a focal point from where each retailer forms his expectations, and thus it is "natural" to assume that they will end up having the same beliefs.

From their behavior in the contract market (realized contract demand) and from knowing retailers' expectations, the producer infers the information possessed by retailers. The information is transmitted from retailers to the producer via differentiated behavior of retailers in the contract market, due to their private information. That is, the aggregate contract demand of the retailers when they have information $\mathrm{p}_{1}$ is different from the aggregate contract demand when they have information $\mathrm{p}_{2}$. Thus, from observing aggregate contract demand the producer can infer the retailers' information. With this inferred. information, the producer decides how much he will produce over and above the amount already committed in the contract market. This production decision determines in turn the true spot price distribution.

The assumption of rational expectations (A9) implies that, given producer's announcement of contract price and spot price distribution, in equilibrium retailers' expectations are the same as the true spot price distribution. Also, any equilibrium with the producer telling a lie has an equivalent equilibrium with the 
producer telling the truth: the producer announces the prices that retailers arrived at from the untruthful announcement. This reasoning is similar to the "Revelation Principle" in the games of incomplete information literature (see Myerson (1979)). Therefore we will concentrate our analysis only on truthful or credible announcements.

There is a very simple way to model expectations equilibrium for credible announcements. Let us describe the following process: producer announces whatever he wants and retailers believe blindly in producer's announcement; as we described two paragraphs above, the retailers' announcement together with retailers' expectations determines the true spot price distribution (which might be different from producer's announcement). The credible announcement requirement (i. e., the rational expectations requirement) is that we are in a fixed point of this process. The set of fixed point of this process can be interpreted as the set of announcements with the property that if retailers believe in producer's announcement then the best the producer can do is to fulfill his announcement. The convenience of this way of modeling rational expectations equilibrium is thar we can deal with a very simple process of expectations formation on the part of the retailers.

Let $x_{i}(\alpha)$ be the amont bought in the spot market, at state of nature $p_{i}$, by retailer $\alpha$, and let $z_{i}($ il) be the amount bought in the contract market by retailer a with information $p_{i}$.

\subsection{Retailers' Behavior}

Retailer a's behavior in the spot market, at state of nature $\mathrm{p}_{i}$, given that he has bought $z_{i}$ units in the contract market can be described as

$$
\max _{x_{i}(\alpha)}\left[x_{i}(\alpha)+z_{i}\right] p_{i}-\frac{\left(x_{i}(\alpha)+z_{i}\right)^{2}}{4(x}-x_{i} x_{i}(\alpha)-q z_{i} .
$$


The solution is

$$
x\left(p_{i}, r_{i}, z_{i}, \alpha\right)=\max \left\{2\left(p_{i}-r_{j}\right) \alpha-z_{i}(\alpha) ; 0\right\}
$$

(7)

$$
\frac{d x_{i}(\alpha)}{d z_{i}(\alpha)}=\left\{\begin{aligned}
-1, & \text { if } x_{i}>0 \\
0, & \text { if } x_{i}=0
\end{aligned}\right.
$$

Expression (7) defines the behavior of retailer $\alpha$ in the spot market as a function of his position $z_{i}(\alpha)$ in the contract market. We will suppress the argument $\alpha$ from the demand functions of retailer $\alpha$ to simplify the notation. Taking his own "spot behavior function" (7) as given, his behavior in the contract market can be described as

$$
\max _{z_{i}}\left[\pi \mid p_{i}\right]=p_{i}\left(x_{i}\left(z_{i}\right)+z_{i}\right)-\frac{\left(x_{i}\left(z_{i}\right)+z_{i}\right)^{2}}{4 \alpha}-x_{i} x_{i}\left(z_{i}\right)-q z_{i} .
$$

This problem is easily solved if we think about it before we go through the mathematics. Recall that retailer $\alpha$ knows today what will be state of nature tomorrow. The expectations assumption implies that what retailer $\alpha$ expects is exactly what spot price tomorrow will be. Thus, if the contract price $q$ is lower than tomorrow's spot price $r_{i}$, retailer buys everything he wants in the contract market (case $x_{i}=0$ ). In this case, the solution to (8) is given by the conditions

$$
p_{i}-\frac{z_{i}}{2 \alpha}-q \leq 0, \quad=\text { if } z_{i}>0
$$

If $r_{i}<q$, then the retailer will buy everything in the spot market (which implies $z_{i}=0$ ). In this case, $x_{i}(\alpha)$ is determined by expression (7) with $z_{i}=0$. The solution is 


$$
p_{i}-\frac{x_{i}}{2 \alpha}-r_{i} \leqslant 0,=\text { if } x_{i}>0
$$

For the case when $r_{i}=q$, retailer $\alpha$ is indifferent between buying on contract or in the spot. The total quantity bought $\left(x_{i}+z_{i}\right)$ will be

$$
p_{i}-\frac{x_{i}+z_{i}}{2 \alpha}-q=p_{i}-\frac{x_{i}+z_{i}}{2 \alpha}-r_{i} \leq 0,=\text { if } \quad x_{i}+z_{i}>0
$$

Because $C^{\prime}(0)=0$, and $p_{i}>0$ for all $i$, we can assume without loss of generality that $0<r_{i}<p_{i}$. That is because if $r_{i}=0$ or $r_{i} \geq p_{i}$ then total producer's revenue equals zero. However, since $p_{i}>0$, there is always a $\left(r_{1}, r_{2}, y\right), i . e ., a$ spot price distribution and a strictly positive quantity transacted in the spot market which would give strictly positive profits to the producer. Thus, indeed, the inequalities (9), (10) and (11), when they occur, are satisfied with equality. That is

$$
z_{i}(\alpha)=2\left(p_{i}-q\right) \alpha, \text { if } q<r:
$$

$$
\begin{aligned}
& x_{i}(\alpha)=2\left(p_{i}-r_{i}\right) \alpha, \text { if } q>r_{i} \\
& 2\left(z_{i}+x_{i}\right) \alpha=2\left(p_{i}-q\right) \alpha=2\left(p_{i}-r_{i}\right) \alpha, \text { if } q=r_{i}
\end{aligned}
$$

Note that if $z_{i}(\alpha)>0$ (which implies $x_{i}(\alpha)=0$ ) for some $\alpha, z_{i}(\alpha)>0$ for all $\alpha$. Also, if $x_{i}(\alpha)>0$ (which implies $\left.z_{i}(\alpha)=0\right)$, for some $\alpha$, then $x i(\alpha)>0$ for all $\alpha$. Thus the aggregate demand is

$$
\begin{array}{ll}
\text { (12a) } & \left(x_{i}=0, z_{i}=p_{i}-q\right), \text { if } q<r_{i} \\
(12 b) & \left(x_{i}=p_{i}-r_{i}, z_{i}=0\right), \text { if } q>0 \\
(12 c) & \left(x_{i}+z_{i}=p_{i}-r_{i}=p_{i}-q\right), \text { if } q=0
\end{array}
$$


4.2. The Producer's Problem and Equilibrium

The producer, in this special case of two states of nature, can choose between getting no information (pooling equilibrium) and getting full information (separating equilibrium). This is so because of the particular structure of uncertainty and information. Either the producer extracts some information or no information. But due to the existence of only two states of nature and the fact that retailers are symmetrically and perfectly informed, if the producer extracts some information then he extracts full information. This too strong result will not remain if we introduce more states of nature and asymmetry of information among retailers.

The pooling equilibrium sets spot prices identical to those found in the case when here was only the spot market and the producer had no advance information $\left(r_{1}^{O}, r_{2}^{\circ}\right)$, and sets the contract price $q$ larger than or equal to the maximum of the spot prices, illustrated in Figure I.

The pooling equilibrium is derived by finding the quantity $x$ to be produced by the uninformed producer which, roughly speaking, equates his marginal cost to his expected marginal revenue. After finding the quantity to be produced, he announces for each state of nature the spot price that maximizes his profits in it. Any $q$ larger than or equal to the maximum spot price is a pooling equilibrium in spot and contract market. That is because any $q<\max _{i}\left\{r_{i}^{0}\right\}$ will induce the retailers to buy on contract when have the information $p_{i}$. This it turn implies that the equilibrium would be separating.

On the other hand, if $q \geq \max \left\{r_{i}^{\circ}\right\}$ then retailers buy nothing in the contract market whatever the realization of information may be. Because retailer's behavior in the contract 
market is identical whatever information they get, the producer cannot infer any information from retailers by observing their behavior in the contract market. Thus, at the time he has to make his production decision the producer is uninformed. Therefore the uninformed producer in the pooling equilibrium is in a position to make his production-pricing decision identical to the uniformed producte, which operates only through the spot market. Thus, $\left(r_{1}^{\circ}, x_{1}\left(r_{1}^{\circ}\right) ; r_{2}^{\circ}, x_{2}\left(r_{2}^{\circ}\right)\right)$ is the optimum production-spot pricing decisior for the producer.

The separating equilibrium is more interesting. From expression (12) we know that $q$ must be not greater than $\max \left\{r_{1}, r_{2}\right.$ ?. If $q>\max \left\{r_{1}, r_{2}\right\}$ then by (12) $z_{i}=0$ for $i=1,2$. Thus, the aggregate contract demand is the same whatever the realization of information may be (i. e., the aggregate contract demand is constant over the space of information), and the producer cannot infer any information by observing retailers' behavior in the contract market.

To prove the main proposition of this section, it is convenient to analyze the equilibrium that would prevail if there were only spot market but the producer were fully informed about tomorrow's state of nature at the time he has to make his production decision. In this case, the spot price equilibrium is the "monopoly price" in the sense that for each state of nature $p_{i}$ the equilibrium price $r_{i}^{O}$ is such that, at this price, marginal revenue equals marginal cost. Formally, the producer would choose $\left(r_{i}, x_{i}\right)$ such that it maximizes.

$$
r_{i} x_{i}-C\left(x_{i}\right) \quad \text { (Producer's profit function) }
$$

$$
\begin{gathered}
\text { s. t. } \\
p_{i}-r_{i}=x_{i}
\end{gathered}
$$




$$
x_{i}^{m}=\frac{p_{i}}{2+b} ; \quad r_{i}^{m}=\frac{(1+b) p_{i}}{2+b} \text {. }
$$

We also define $r_{i}^{c}$ as the competitive price that would arise at state of nature $p_{i}$ if the producer were fully informed before making his production-pricing decision but acted competitively. Formally, the producer would choose $\left(r_{i}, x_{i}\right)$ such that

$$
\begin{array}{ll}
C^{\prime}\left(x_{i}\right)=r_{i} & (M C=\text { price }) \\
\text { s.t. } & \\
P_{i}-r_{i}=x_{i} & \text { (demand curve) }
\end{array}
$$

with solutions

$$
x_{i}^{c}=\frac{p_{i}}{i+b} ; \quad r_{i}^{c}=\frac{b p_{i}}{1+b}
$$

The solutions $\left(r_{i}^{m} ; x_{i}^{m}\right),\left(r_{i}^{c}, x_{i}^{c}\right)$ are illustrated in Figure I.

Proposition 4.1: Let $\left(r_{1}^{*}, r_{2}^{*}, q\right)$ be an equilibrium price system for the credible announcement model. If equilibrium is separating then for all realization of information $p_{i}$ such that the retailers buy in the contract market a strictly positive quantity of product then it must be the case that the contract price is smaller than the price charged by a fully informed competitor, $i . e ., q 6 r_{i}^{c}$.

Proof: see appendix I.

The intuition behind this proposition is the following. For a state of nature $p_{i}$ such that retailers buy in the contract market (which means $r_{i}^{*} \geq q$ ), if $q$ is bigger than $r_{i}^{c}$ it gives the producer the opportunity to extract extra profits by selling some units in the spot market (which implies $r_{i}^{*}<q$ ), which generates a contradiction. 
Proposition 4.1 gives a partial characterization of the contract price $q$ in terms of the spot prices $r_{i}^{c}, s$. The next proposition will completely characterize $q$. However, before we announce and prove proposition 4.2 , it is convenient to introduce the idea of qualitative behavior. We say that retailer " has the same qualitative behavior when he faces two different price systems if whenever he buys (does not buy) at some market at one price system he also buys (does not buy) at the other price system, for all possible realizations of state of nature $p_{i}$.

Let $I^{*}=\left\{i \mid r_{i}^{*} \geq q\right\}$.

Proposition 4.2: Let $\left(r_{1}^{*}, r_{2}^{*}, q\right)$ be a separating equilibrium. Fix $r_{1}^{*}$ and $r_{2}^{\star}$ and let $q$ vary. Then

$$
q=\min _{I^{*}}\left\{r_{i}^{c}\right\}
$$

is the best separating equilibrium among those separating equilibria with the same qualitative behavior as $\left(r_{1}^{*}, r_{2}^{*}, q\right)$.

Prof: see appendix I.

The intuition for this result is immediate. Because the producer has to charge the contract price below the competitive prices for the states of nature where retailers actually buy in the contract market, the best policy for him is to charge the highest possible since the more the prices are below the competitive price, the smaller the producer's profits.

Propositions 4.1 and 4.2 completely characterizes the contract price $\mathrm{q}$ when the equilibrium is separating. But the equilibrium price system also involves the spot price distribution. The next proposition characterizes the whole equilibrium price system for the separating equilibrium. 
Proposition 4.3: (1) If $r_{2}^{m}>r_{1}^{c}$ then the best separating equilibrium is $r_{1}^{*} \geq q_{i} r_{2}^{*} \geq q ; \quad q=r_{2}^{c}$.

(2) If $r_{2}^{m} \leqslant r_{1}^{c}$ then the best separating equilibrium is $r_{1}^{*} \geq q ; \quad r_{2}^{*}=r_{2}^{m} ; q=r_{1}^{c}$.

Proof: see appendix I.

The key parameter that determines if the best separating equilibrium will be of the first or second kind is the comparison between the price that a fully informed producer behaving as a monopolist would charge in the lowest state of nature $\left(r_{1}^{m}\right)$ and the price that a fully informed producer behaving as a competitor would charge in the highest state of nature $\left(r_{1}^{c}\right)$. If $r_{2}^{m}$ is higher than $r_{1}^{c}$ then the separating equilibrium will be of the first kind. In this case the contract price is equal to the price charged in the lowest state by a fully informed competitive producer $\left(r_{2}^{c}\right)$. The spot prices are any value above the contract price.

The more interesting case is the second kind of separating equilibrium. This case occurs whenever the spot price that a fully informed monopolist would charge in the lowest state of nature $\left(r_{2}^{m}\right)$ is not bigger that the spot price that a fully informed competitor would charge in the highest state of nature $\left(r_{1}^{c}\right)$. For this kind of equilibrium the contract price is equal to $r_{1}^{c}$, the spot price in the highest state of nature is any value above it, and the spot price in the lowest state of nature is the price that a fully informed producer behaving as a competitor would charge.

Even though we have not been able to fully characterize the values of the parameters which would favour one kind of separating equilibrium over another, proposition 4.3 suggests that the "value of information" is crucial. By "value of information" we mean the difference between the two states of nature, captured by the linear coefficient of the aggregate demand $p_{i}$. 
A sozution of the credible announcement version of the model with both spot and contract markets is found by comparison between an optimum separating equilibrium and an optimum pooling equilibrium. A solution is the equilibrium which gives higher expected profits to the producer between them.

Any equilibrium solution of the credible announcement version of the model with both spot and contract markets, whatever kind it is (separating or pooling), always leaves the producer better off than the equilibrium in the "non-contract market" model. This is because the equilibrium, if it is pooling, gives the same expected return to the producer as the equilibrium of the case with no contract market. And the equilibrium will be separating only if there are separating equilibria which dominate all pooling equilibria from the producer's viewpoint. Summarizing this result

Proposition 4.4: The producer is always better off under the existence of both contract and spot market (but no binding announcement) than under the existence of only the spot market.

In some of these credible announcement equilibria, the contract market (or the spot market) may always be non-operative, i. e., whatever the realization of the state of nature may be, the contract market (or the spot market) transaction is zero. In the pooling, the contract market transaction $z_{i}$ is equal to zero, whatever is the state of nature. In the separating equilibrium for the case when $r_{2}^{m}>r_{2}^{c}$, spot transaction is equal to zero whatever is the state of nature. Only in the separating equilibrium for the case when $r_{2}^{m} \leqslant r_{1}^{c}$ we have both markets operative.

Clearly the move interesting case is the case when we have separating equilibrium with both markets operative. In appendix II we build an example where we have this kind of equilibrium. 


\section{BOTH SPOT AND CONTRACT MARKETS: \\ BINDING ANNOUNCEMENT EQUILIBRIUM}

The structure of the model developed in this section is identical to the one developed in section IV, except for one crucial assumption.

A13. When the producer markes his announcement about prices, he must fulfill it.

This assumption has been largely used in models of contract markets (see for example Kihlstrom and Postlewaite [1983]). It is very convenient technically because it solves the expectations problem trivially. However, if there are incentives for charging prices in the future different from those announced, and if there is no costless way of punishing deviation from announcement, the binding announcement assumption becomes too restrictive. Because the binding announcement model has been studied elsewhere, we will give a concise exposition of the main results with respect to our characterization of equilibrium and its normative properties (from the viewpoint of the producer). Our analysis will consist of the following two propositions.

Proposition 5.1: Under the assumption A1-A13 the equilibrium price system for the binding announcement version is $r_{i}^{b} \geqslant r_{i}^{m}$; $r_{2}^{b}=r_{2}^{m} ; \quad q=r_{1}^{m}$, where $r_{i}^{b}$ is the spot price solution at state of nature $p_{i}$ for the binding announcement model.

Proof: see appendix I

Proposition 5.2: Under assumptions A1-A13, the producer is always better off if he can be bound by his announcement than if he cannot. 
Proof: Any feasible price system announcement is a rational expectations equilibrium in the binding announcement model, where feasible announcements are those which the producer can fulfill. In particular, the rational expectations equilibrium of the credible announcement model is a feasible price system announcement for the binding announcement model.

\section{CONCLUSIONS}

In this paper we build models which try to reflect some key features of intermediate industrial product inarkets. Because all participants in those markets are firms the natural assumption about behavior with respect to risk is risk-neutrality. Another important feature of those markets is the presence of asymmetry of information.

There are some difficulties when the assumptions of riskneutrality and asymmetry of information are put together. Demand and supply are or zero or plus/minus infinity. 'I'he way we circumvent these difficulties is via the introduction of the assumption of impossibility of reselling.

Another important assumption of our models is that we assume a non-auctioneer process of price formation. In our models, prices are announced by the seller and the buyer has discretion about the quantity transacted. Here we follow the advice of Rothchild and Stiglitz [1976], who suggest that this is the most used process of price formation in the real world.

The models built in this paper are the simplest versions possible which can address most of the issues that arise in more general environments. In this paper there are only two possible states of nature, the retailers being symmetrically and perfectly informed. 
In this paper there are no welfare propositions. There are basically two justifications for this. First, it is because we take a "positive" approach. The monopolist producer and seller has the power to open or close markets. Therefore the institutional arrangement that will prevail is the one that maximizes producer's profits, rather than social welfare. And typically the solution of the maximization of producer's profits is different from the solution of maximization of social welfare. Second, even though it might be feasible to make welfare analysis for the simple case analysed in this paper, it would not be feasible for more general environments such as finite but arbitrary number of states of nature, imperfect information and asymmetric information among retailers.

The models also have important limitations. For example, the assumption of one monopolist producer plays an important role in allowing us to reach our results. If we relax this assumption, then the mechanism of transference of information (size of aggregate demand to each producer) ${ }^{5}$ is blurred to a degree which may not allow the producers to infer any information from quantities transacted.

We believe that the directions of building useful models of intermediate product markets with asymmetry of information where there is the possibility of various producers is an important direction of research. Also promising is the research on quantities such as the information transmission mechanism from the particular framework of this paper. For example, one could investigate the macroeconomic role of inventories and/or orders in the production decisions of the production side of an economy which operates with a production lag.

5 By aggregate demand for each producer we mean the total transaction on the contract market of each producer. 


\section{APPENDIX I}

Proof of Proposition 4.1

Let $i$ ' be such that $z_{i}>0$ if $r_{i}^{*} \geq q$. Suppose that $q>r_{i}^{c}$. If realization of information is $p_{i}$, buy on contract the ammount $z_{i},>0$ at price $q>r_{i}$.. After the producer gets the contract order, he knows that tomorrow's state of nature will be $p_{i}$, . Hence in the spot market tomorrow the producer will face the residual demand $x_{i},=p_{i},-r_{i},-z_{i},=q-r_{i}$, . Because the producer's marginal cost after contract commitments is bz ${ }_{i},\left(<r_{i},<q\right)$, he has incentives to produce some extra units and sell them in the spot market at spot price $r_{i}$, such that $q>r_{i},>r_{i}^{c}$. Indeed ve can calculate the amount produced to be sold in the spot market at state of nature $p_{i}$, . It is

$$
\begin{aligned}
& y=\underset{x_{i}, \geqslant 0}{\arg \max } r_{i^{\prime}} x_{i},-\frac{b\left(z_{i^{\prime}}+x_{i, 1^{\prime}}\right)^{2}}{2} \\
& \text { s. } t \text {. } \\
& r_{i}{ }^{\prime}=q-x_{i}{ }^{\prime}
\end{aligned}
$$

where $y_{i}$ represents production to sell in the spot market at state of nature $i '$. Because $q>C^{\prime}\left\langle z_{i},\right\rangle$ we have that $y_{i^{\prime}}=\left(q-b z_{i}\right)^{\prime} / 3>0$, which in turn implies that $r_{i}^{*}<q$. This contradicts supposition $z_{i},>0$. 
Proof of proposition 4.2

From proposition 4.1 we know that

$$
q \leq \min _{I^{*}}\left\{r_{i}^{c}\right\}
$$

In the remaining of this proof we will suppress the subscript $I_{*}$ from the expression min $\left\{r_{i}^{c}\right\}$, but we will still be calculating the min only over $i$ that belongs to $I^{*}$. Suppose $q<\min \left\{r_{i}^{G}\right\}$. Recall that by definition $C^{\prime}\left(p_{i}-r_{i}^{c}\right)=r_{i}^{c}$ where $p_{i}-r_{i}^{c}$ is the quantity demanded by the retailers if there were no contract market and the producer were a fully informed competitor.

$$
\text { Since } q<\min \left\{r_{i}^{c}\right\} \text { and } C^{\prime}>0, c^{\prime}\left(p_{i}-q\right)>q^{\prime} \text { for all } i
$$
which belongs to $I^{\star}$. That is, producer's marginal cost at state of nature $p_{i}$ such that $i$ belongs to $I^{*}$ is (a lot) larger than marginal revenue. Thus, if producer raises $q$ to $\bar{q}$ such that $q<\bar{q} \leq \min \left\{r_{i}^{c}\right\}$, the producer will increase his profits at all states of nature such that $i$ belongs to $I^{\star}$. Also it does not affect producer's profits at the other states of nature because for $i$ which does not belong to $I^{*}, r_{i}^{*}<q$, which implies that $r_{i}^{*}<\tilde{q}$, and therefore the retailers continues to buy only in the spot market the quantity $p_{i}-r_{i}^{*}$ at the price $r_{i}^{*}$ under the price systems $\left(r_{1}^{*}, r_{2}^{*}, q\right)$ and $\left(r_{1}^{\star}, r_{2}^{\star}, \bar{q}\right)$. 
Proof of proposition 4.3

\section{Proof: (1)}

From proposition 4.1 we know that $q \leq r_{1}^{c}$. Now, if $q \leq r_{2}^{*}$ then $q \leq r_{2}^{c}$ (by proposition 4.1 also). If $q>r_{2}^{*}$ $\left(\rightarrow q \leq r_{1}^{*}\right)$ we get by proposition 4.2 that $q=r_{1}^{c}>r_{2}^{c}$. suppose that state of nature $p_{2}$ has realized. Retailers facing $q>r_{2}^{*}$ will choose to buy in the spot market at the price $r_{2}^{*}$. But once producer has observed that contract demand was zero he infers that retailers' information is $\mathrm{P}_{2}$ and then he decides which will be his true production-pricing decision for this state or nature. That is, he will choose $\left(r_{2}^{*}, x_{2}^{*}\right)$ such that it maxinizes

This problem is equivalent to that described in expression (13), thus the solution is $\left(r_{2}^{m}, p_{2}-r_{2}^{m}\right)$. But $r_{2}^{*}=r_{2}>r_{1}^{c}=q>r_{2}^{*}$, a contradiction. Hence $\left(r_{1}^{*}, r_{2}^{*}, q\right)$ could not be a credible announcement.

Observe also that $q>r_{1}^{*}\left(\rightarrow q \leq r_{2}^{*}\right)$ cannot be also a credible announcement equilibrium. That is because $r_{1}^{m}>r_{2}^{m}>r_{2}^{c}=q$. Therefore, when realization of information is $p_{1}$ retailers buy nothing in the contract market, revealing their information to the producer. Once the producer gets the information he will make his 
spot production-pricing decision $\left(r_{1}^{*}, x_{1}^{*}\right)$ in order to maximize

$$
\begin{gathered}
r_{1} x_{1}-c\left(x_{1}\right) \\
\text { s. t. } \\
r_{1}=p_{1}-x_{1}
\end{gathered}
$$

which is equivalent to the problem described in expression (13), with solution $r_{1}^{*}=r_{1}^{m}>r_{2}^{c}>r_{1}^{*}$. Hence, $r_{1}^{*}<q=r_{2}^{c}$ cannot be a credible announcement equilibrium. Therefore, if $r_{2}^{m}>r_{1}^{c}$ then any credible announcement equilibrium must be of the form $r_{1}^{*} \geq q$; $r_{2}^{*} \geq q ; \quad q=r_{2}^{c}$.

But every price system $\left(r_{1}^{*}, r_{2}^{*}, r_{2}^{c}\right)$ with $r_{1}^{*} \geqslant r_{2}^{c} ; r_{2}^{*} \geqslant r_{2}^{c}$ gives the same expected profits to the producer. That is because all transactions are made in the contract market, at the price $r_{2}^{c}$, and no transactions are made in the spot market.

We will show first that $r_{1}^{*}=r_{1}^{c} ; r_{2}^{*}=r_{2}^{m} ; \quad q=r_{1}^{c}$ is a credible announcement equilibrium. Then we will show that there is no other credible announcement equilibrium which gives more profits to the producer than $\left(r_{1}^{c}, r_{2}^{m}, r_{1}^{c}\right)$.

If producer announces $\left(r_{1}^{*}, r_{2}^{*}, q\right)=\left(r_{1}^{c}, r_{2}^{m}, r_{1}^{c}\right)$ then if realizaton of information is $p_{1}$, retailers buy in the contract market the quantity $x_{1}^{c}=p_{1} /(1+b)$ at the price $r_{1}^{c}=b p_{1} /(2+b)$ (from expression (16)). Note that $x_{1}^{c}>x_{1}^{m}$, where $x_{1}^{m}=p_{1} /(2+b)$ (from expression (14)), and that at $x_{1}^{m}$ the strictly decreasing marginal revenue at state of nature $p_{1}$ is equal to the strictly 
increasing marginal cost at $x_{1}^{m}$. Hence at $x_{1}^{c} M R_{1}\left(x_{1}^{C}<M C\left(x_{1}^{c}\right)\right.$. since the residual spot demand in state of nature $p_{1}$ is

$$
\begin{cases}r_{1}^{c}-r_{1}, & \text { if } r_{1} \leqslant r^{c} \\ 0, & \text { otherwise }\end{cases}
$$

while the producer's marginal cost for the first unit of product produced to sell in the spot market at state of nature $p_{1}$ is $r_{1}^{c}$, the producer's optimum decision for the spot market at state of nature $\mathrm{p}_{1}$ is to charge a price larger than $\mathrm{r}_{1}^{\mathrm{c}}$ and selling zero units.

If the state of nature is $p_{2}$, retailers buy nothing in the contract market, signaling their information to the producer before he has made his production-spot pricing decision. Therefore he is in the same position as the fully informed monopolist producer that operates only through the spot market. Hence his decision will be $r_{2}^{*}=r_{2}^{m}$.

This completes the proof that $\left(r_{1}^{*} \geq r_{1}^{c} ; \quad r_{2}^{*}=r_{2}^{m} ; \quad q=r_{1}^{c}\right)$ is a credible announcement equilibrium. It remains to be shown that it is a best credible announcement equilibrium from the producer's viewpoint. But this is trivial. By proposition 4.1 the producer cannot charge $q>r_{1}^{c}$, which implies that the produccr will be selling too many products in the state of nature $p_{1}$. Therefore the best the producer can do in state of nature $p_{1}$ is to charge the maximum $\mathrm{q}$ consistent with a credible announcement equilibrium, i. e., $q=r_{1}^{c}$, and choose $r_{1}^{*} \geq r_{1}^{c}$. 
With respect to state of nature $p_{2}$, the best he cando is to extract full monopoly profits, that is, to charge $r_{2}^{*}=r_{2}^{m}$.

Proof of proposition 5.1

We will first show that $\left(r_{1}^{b}=r_{1}^{m}, r_{2}^{b}=r_{2}^{m}, q=r_{1}^{m}\right)$ is a best announcement for a fully informed monopolist. Then we will show that it is also a feasible equilibrium announcement for the uninformed monopolist. Since the profits of an uninformed monopolist cannot be larger than the profits of a fully informed monopolist. That is because the informed monopolist can act as an uninformed monopolist (but the reverse is not true). Therefore $\left(r_{1}^{b}=r_{1}^{m}\right.$, $r_{2}^{b}=r_{2}^{m}, q=r_{1}^{m}$ ) is as profit-maximizing announcement for the uninformed monopolist. And any announcement of the form $\left(r_{1}^{b} \geq r_{1}^{m}\right.$, $r_{2}^{b}=r_{2}^{m}, q=r_{1}^{m}$ ) gives the same profits to the producer.

Let us suppose that the producer is fully informed at the time he has to make his production-pricing decision, but he operates only through the spot market. Then, from expressions (13) and (14) $r_{1}^{b}=r_{1}^{m}, r_{2}^{b}=r_{2}^{m}$. Now let us suppose that the producer decides to open the contract market. From expression (12) he knows that if $q \leq r_{i}$ then $z_{i}>0, x_{i}=0$, while if $q>r_{i}$ then $z_{i}=0, x_{i}>0$. Therefore, if he announces $q>r_{1}^{m}$, he cannot increase his profits at state of nature $p_{i}$ while if he announces $q<r_{i}^{m}$ he lowers his profits at state of nature $p_{i}$. Therefore $q=\max _{i}\left\{r_{i}^{m}\right\}$ is a best contract price announcement.

Let us show now that $\left(r_{1}^{b}=r_{1}^{m}, r_{2}^{b}=r_{2}^{m}, q=r_{1}^{m}\right)$ is a feasible equilibrium announcement for the case when the producer is an 
uninformed monopolist. If realization of information is $p_{1}$, then $z_{1}=p_{1}-r_{1}$, while if realization of information is $p_{2}$, then $q>r_{2}^{m}$ which implies that $z_{2}=0$. Therefore, the producer can infer the information possessed by the retailers at useful time and so he can fulfill the spot demand $x_{2}=p_{2}-r_{2}^{m}$. Thus $\left(r_{1}^{b}=r_{1}^{m}\right.$, $r_{2}^{b}=r_{2}^{m}, q=r_{1}^{m}$ ) is a feasible equilibrium for the case that the producer is an uninformed monopolist.

Now note that the producer's expected profits is the same for any announcement of the form $\left(r_{1}^{b} \geq r_{1}^{m}, r_{2}^{b}=r_{2}^{m}, q=r_{1}^{m}\right)$, and any announcement of this form is a feasible equilibrium for the case when the monopolist is uninformed. This completes the proof. 


\section{APPENDIX I I}

In this appendix we will introduce a modification of the model described in section II. We will assume the aggregate demand for the intermediate product to be of the following form

$$
x_{i}= \begin{cases}p_{i}-a r_{i} & (a>0), \text { if } r_{i}<q \\ 0, & \text { otherwise }\end{cases}
$$

While aggregate contract demand is

$$
z_{i}= \begin{cases}p_{i}-a q, & \text { if } r_{i} \supseteq q \\ 0, & \text { otherwise }\end{cases}
$$

The parameter a captures the slope of the aggregate demand curve. The higher the value of a the steeper the aggregate demand curve. While the introduction of this parameter allows us to make inferences about an economically important characteristic of market structures, it requires a few sacrifices. Instead of assuming the cost structure of the firms as the "primitives" in the market for the intermediate product and deriving from them the demand and "supply" for the product, we now will assume that the aggregate product demand is the primitive (the producer cost function will still be the primitive concept of the supply side of the market). However, it should be transparent that the results for the credible announcement model - developed in section IV - are still valid for this slight modification. 
Other relevant parameters that we will focus in this appendix are: $b^{6}$ (see assumption 10), which captures the slope of the producer's marginal cost curve (the higher the value of $b$ the steeper the producer's marginal cost curve); 0 , the probability of occurrence of state of nature $p_{1}$.

In the exercise of this appendix we will investigate the values of these parameters, as well as the values of the parameters $\mathrm{p}_{1}$ and $\mathrm{p}_{2}$ that favor the credible announcement equilibrium with both the spot and the contract markets operative such that $x_{1}=x_{2}$ is the pooling equilibrium. This case imposes on us further difficulties because it imposes bounds on the distance between $p_{1}$ and $p_{2}$. We will first investigate the pooling equilibrium; then we will investigate the separating equilibrium of the kind with both the contract market and the spot market operative, which will be referred to hereafter as separating equilibrium. Finally, we will investigate the value of the parameters which favours one type of equilibrium over the other. By inverting the aggregate demand function, we get, in the pooling equilibrium (i. e., $r_{i}<q$, for $i=1,2)$.

(A1)

$$
r_{i}=\frac{p_{i}-x_{i}}{a}
$$

Thus the producer's profit function in the pooling equilibrium case is

$$
\pi=\theta\left[\frac{p_{1}-x_{1}}{a} x_{1}\right\}+(1-\theta)\left[\frac{p_{2}-x_{2}}{a} x_{2}\right\}-b\left[\max \left(x_{1}, x_{2}\right)\right]^{2} .
$$

${ }^{6}$ As a matter of fact, we will make the following innocuous change in the producer's cost function: $c(y)=b y^{2}(b>0)$. 
If at the solution of the maximization of (A2) we have that $x_{1}=x_{2}=x$, then this solution is the same as the solution to the following problem

(A3) $\max \theta\left\{\frac{p_{1}-x}{a} x\right\}+(1-\theta)\left\{\frac{p_{2}-x}{a} x\right\}-b x^{2}$.

That is, the solution of the expected profit maximization of the constrained problem (A3) - the case when the producer is forced to sell the same quantity in both states of nature - is the same as the solution of the unconstrained problem (A2). The first order condition for the constrained problem is

$$
\pi^{\prime}=\theta\left\{\frac{p_{1}-2 x}{a}\right\}+(1-\theta)\left\{\frac{p_{2}-2 x}{a}\right\}-2 b x=0
$$

which implies the optimum solution $\left(x, r_{1}, r_{2}\right)$

$$
\begin{aligned}
& x=\frac{\theta p_{1}+(1-\theta) p_{2}}{2(1+a b)}=\frac{E[p]}{2(1+a b)} \\
& r_{1}=\frac{2 p_{1}(1+a b)-E[p]}{2 a(1+a b)} \\
& r_{2}=\frac{2 p_{2}(1+a b)-E[p]}{2 a(1+a b)}
\end{aligned}
$$

If at the pooling equilibrium $x_{1}=x_{2}$, then the profit of the producer is

$$
\pi_{p}=\operatorname{Br}_{1} x+\left(1-\operatorname{los}_{2} x-b x^{2}=\frac{E[p]^{2}(1+a b)}{4 a(1+a b)^{2}}\right. \text {. }
$$

The following lemma analyses the conditions for the pooling equilibrium to be of the type $x_{1}=x_{2}$. 
Lemma A1: In our example, a necessary (sufficient) condition for the pooling equilibrium of the unconstrained problem to be of the type $x_{1}=x_{2}=x_{\text {, }}$ is that the marginal revenue at each state of nature evaluated at the solution of the constrained problem must be positive (strictly positive).

\section{Proof: (Necessity)}

If at the lower state of nature, say $\mathrm{p}_{2}, \mathrm{MR}_{2}(\mathrm{x})<0$, then if the producer is allowed to sell different units at different states of nature he will want to sell less than $x$ at state of nature $p_{2}$. But when he is allowed to sell less than $x$ in state of nature $p_{2}$, he will be wanting to produce and sell more than $x$ at state of nature $p_{1}$. That is because now he can avoid the deadweight loss of being forced to sell in bad states. Thus $x_{1}>x_{>}>x_{2}$. Hence we are not in the case when $x_{1}=x_{2}$.

\section{(sufficiency)}

Because $M R_{i}(x)>0$ for $i=1,2, x$ is in the interior of the set $x=\left\{x \mid M R_{i} \geq 0\right.$, for $\left.i=1,2\right\}$. Recall that our assumption of linear strictly increasing producer's marginal cost curve and linear (strictly) increasing demand curve, the expected profit function is strictly concave, thus has a unique solution. Also the linear strictly decreasing demand function implies that $x$ is convex.

Note that in the set $x$ the constrained an the unconstrained problem are the same. By assumption the constrained problem has a local (and global) maximum in the interior of $x$. Since the unconstrained problem has at most one local (and global) solution and it has a local solution in the interior of $x$, we conclude that the solution of the unconstrained problem is such that $x_{1}=x_{2}$.

Because $p_{1}>p_{2}$, in order to verify under which conditions the solution of the unconstrained problem is such that $x_{1}=x_{2}=x_{\text {, }}$ we need to see if 


$$
\frac{d\left(x_{2} x\right)}{d x}>0
$$

evaluated at the solution of the constrained problem. That is

$$
\frac{d}{d x}\left[\frac{p_{2}-x}{a} x\right]=\frac{p_{2}}{a}-\frac{2 E[p]}{2 a(1+a b)}>0
$$

(A4)

$$
p_{1}>p_{2}>\frac{\theta p_{1}}{\theta+a b}
$$

Expression (A4) illustrates the limitation on the distance between $p_{1}$ and $p_{2}$ imposed by our requirement that we are in a pooling equilibrium of the type $x_{1}=x_{2}=x$. "Note that by choosing a low enough value of $\theta$ we can guaranteee that this constraint is satisfied for any value of $p_{1}>p_{2}$. It will occur that the restriction of the values of $p_{1}$ and $p_{2}$ for the separating equilibrium is in the opposite direction, $i . e ., p_{1}$ and $p_{2}$ must be sufficiently apart.

Now we turn to investigate the separating equilibrium. If the equilibrium is separating, we know from proposition 4.3 that the production-pricing decision that the producer makes in state of nature $p_{1}$ must be the same as in the case when the producer is fully informed at the time he has to make his production-pricing decision but operates only through the spot market and behaves competitively, i.e., charges price equal marginal cost and produces the quantity such that marginal cost equals aggregate demand.

$$
\begin{aligned}
& \text { Price }=M C\left(x_{1}\right) \\
& r_{1}=2 b x_{1}
\end{aligned}
$$

$$
\mathrm{x}_{1}=\frac{\mathrm{p}_{1}}{1+2 \mathrm{ab}}
$$




$$
r_{1}^{*} \geq q=\frac{2 b p_{1}}{1+2 a b}
$$

We also know by proposition 4.3 that the spot price in state of nature $\mathrm{p}_{2}$ is the same as the spot price charged by a monopolist that operates only through the spot market but is fully informed about the state of nature at the time he has to make his production-princing decision. That is

$$
M R_{2}\left(x_{2}\right)=M C\left(x_{2}\right)
$$

$$
x_{2}=\frac{p_{2}}{2(1+a b)}
$$

The producer's profit in the separating equilibrium is

$$
\begin{aligned}
& \pi_{s}=0\left[q x_{1}-c\left(x_{1}\right)+(1-\theta)\left[r_{2} x_{2}-c\left(x_{2}\right)\right]=\right. \\
& \theta \frac{b p_{1}^{2}}{(1+2 a b)^{2}}+(1-\theta) \frac{p_{2}^{2}(1+a b)}{4 a(1+a b)^{2}} .
\end{aligned}
$$

According to proposition 4.3, for a separating equilibrium to exist it is necessary that the spot price at state of nature $p_{2} \quad\left(r_{2}^{m}\right)$ be lower than contract price. That is, (from (A6) and (A8) ).

$$
\begin{gathered}
r_{2} x_{2}-c\left(x_{2}\right) \\
\text { s. t. } \\
r_{2}=p_{2}-x_{2}
\end{gathered}
$$

As we noted previously, while expression (A4) imposes limitations on the distance between $p_{1}$ and $p_{2}$, expression ( $A 9$ ) requires a minimum distance between them for a separating equilibrium to exist. Thus, it is important to answer the following question: Is there a vector $\left(p_{1}, p_{2}\right)$ such that (A4) and (A9) 
area satisfied simultaneously? Fortunately, the presence of the additional parameters give enough flexibility. Expressions (A4) and (A9) together imply

( $\mathrm{A} 10)$

$$
\frac{\theta p_{1}}{\theta+a b}<p_{2}<\frac{4 a(1+a b) p_{1}}{(1+2 a b)^{2}}
$$

Is $\theta /(\theta+a b)<4 a(1+a b)(1+2 a b) 2$ for some values of $a b$ and $\theta$ ?

$$
\theta(1+2 a b)^{2}<4 a(1+a b)(\theta+a b)
$$

(A11)

$$
\theta\left[(1+2 a b)^{2}-4 a(1+a b)\right]<4 a(1+a b)
$$

By taking a low enough value of $\theta$ we can guarantee that (A11) is verified. Now we turn to investigate the values of the parameters which give higher expected profit to the producer in the separating equilibrium than in the pooling equilibrium.

(A12)

$$
\begin{aligned}
& \pi_{s} \geq \pi_{p}, \text { i.e., } \\
& p_{1}^{2}\left(4 a b+4 a^{2} b^{2}-\frac{\theta}{1-\theta}\right)+p_{2}\left(1+4 a b+4 a^{2} b^{2}\right)\left(p_{2}-2 p_{1}\right) \geq 0 .
\end{aligned}
$$

Expressions (A12) and (A10) describe the range of values of the parameters which give the separating equilibrium. Expression (A10) says when the "potential" separating equilibrium of the type $x_{1}=x_{2}=x$ exists, and expression (A12) describes the range of values of the parameters which makes the expected profit of the producer higher under the separating equilibrium than under the. pooling equilibrium. The word "potential" means that the separating equilibrium $\left(q, r_{1}, r_{2}\right)$ is consistent in the sense that if the producer announces $\left(q, r_{1}, r_{2}\right)$, then $\left(r_{1}, r_{2}\right)$ is the optimal spot price distribution, but the expected profit of the producer under a potencial separating equilibrium may be lower than the pooling equilibrium. 
Generally speaking, the separating equilibrium will dominate the pooling equilibrium if $p_{2}$ is small and $p_{1}$ is large (assuming $\left.4 a b+4 a^{2} b^{2}>\theta /(1-\theta)\right)$. Also, the larger the value of a (i.e., the steeper the aggregate demand curve), the larger the value of b (the steeper the producer's marginal cost curve), the larger will be the producer's expected profitinthe separating equilubrium relative to the pooling equilibrium. Finally a smaller value of $\theta$ favors the occurrence of separating equilibrium.

Recall that to satisfy expression (A10) a larger enough $p_{1}$ with respect to $\mathrm{p}_{2}$, and a low enough $\theta$, are required. Thus, fortunately, the set of values of the parameters $p_{1}, p_{2}$ and $\theta$ which satisfy expression ( $A 10$ ) has non-empty intersection with the values of the parameters which satisfy expression (A12). 


\section{REFERENCES}

AZARIADIS, c., "Implicit Contracts and Underemployment Equilibria", Journa 1 of Political Economy, vol. 83, December, pp. 1183-1202, 1975.

"Employment with Ascmmetric Information", Quarterly Journal of Economics, supplement, 1983.

CHARI, V., "Involuntary Unemplosment and Implicit Contracts", Quarterly Journal of Economics, supplement, 1983.

GREEN, J. and C, KAHN, "Wage-Emplosment Contracts", Quarterly Journal of Economics, supplement, 1983.

GROSSMAN, S., "The. Existence of Futures Markets, Noisy Rational Expectations, and Informational Externalities", Review of Economic Studies, vol. 44, October, pp. 431-449, 1977.

"An Introduction to the Theory of Rational Expectations Under Astmmetric Ini mation", Review of Economic Studies, vol. 68, October, pp. 541-559, 1981.

GROSSMAN, S. and 0. HART, "Implicit Contracts Under Asymmetric Information", Quarterly Journal of Economics, supplement, 1983.

HICKS, J., Value and Capital. Second edition, Oxford University Press, 1946.

HIRSHLEIFER, J., "The. Private and Social Value of Ingormation and the Reward to Inventive Activity", American Economic Review, vol. 61, May, 1971.

KEYNES, J., Treatise on Money, vol. II. London: Momillan \& Co, 1930.

KIHLSTROM, R. and A. POSTLEHAITE, "Equilibrium in a Securities Market with a Dominant Trader Possessing Inside. Information", CARESS Working Paper 83-05, University of Pennsylvania, mimeo, 1983.

MYERSON, R., "Incentive Compatibility and the Bargaining Problem", Econometrica, vol. 47, pp. 61-73, 1979.

ROTHCHILD, M. and J. STIGLITZ, "Equilibrium in Competitive Insurance Markets: an Essay on the. Economics of Imperfect Information", Quarterly Journal of Economics, vol. 9C, 629-650, 1976. 
SPENCE, M., "Non-linear Prices and Welfare", Journal of Public Economics, vol. 8. pp. $1-18,1977$.

STIGLER, G. and J. KINDAHL, The Behavion of Industrial Prices, National Bureau of Economic Research, New York, 1970.

WACHTER, M. and O. WILLIAMSON, "Obligational Markets and the Mechanics of Inflation", Bell Journal of Economics, vol. 9, Autumn, pp. 549-571, 1978.

WILLIAMSON, 0., "Transaction-Cost Economics: The Governance of Contractual. Relations", Journal of Law and Economics, October, pp. 233-261, 1979. 
